\title{
Drought Impact Assessment on Vegetation over Sudano-Sahelian Part of Nigeria
}

\section{*11FABEKU, BB; FALEYIMU OI}

\author{
${ }^{1}$ Ondo State University of Science and Technology, Okitipupa. Ondo State, Nigeria \\ Corresponding author's E-mail and Phone number: blesong4u@yahoo.com, +2348139222415
}

\begin{abstract}
This study evaluated the vegetation response to drought over the Sudano-Sahelian part of Nigeria. Landsat and monthly rainfall data with boundary map shapefile data. The results of SPI analysis revealed that the drought saga of the 70s and 80 s was also experienced over the study area but later reversed in the 90 s towards the $21^{\text {st }}$ century as the result show a rapid decline in its occurrence which indicates improvement in rainfall. On the other hand, the vegetation response analysis also depicted that the year 1986 was a dry year over the study area as the spatial extent cover by the vegetation was much less compared to the bare-surface. But in the 1990s, greenness has returned to the areas that were previously bare soil, an indication of improvement in rainfall amount over the area. The study therefore concluded that there exists a kind of inverse relationship between drought intensity and vegetation growth and time lag in their response to dry or wet condition. (C) JASEM https://dx.doi.org/10.4314/jasem.v21i6.24
\end{abstract}

Keywords: Drought Occurrence, Vegetation response, Standardize Precipitation Index (SPI), Normalized Precipitation Index (NDVI), Greenness Index (GI), Drought Spatial Map

The drastic reduction in the Sahelian precipitation in the early 60 s which began to retreat in the early 90 s is no more news (Agnew, 2000). Extreme Arid condition prevails over Sahelian part of Nigeria and caused a sudden break of early rainfall, poor spatiotemporal distribution of precipitation over the region (Hess et al., 1995). This was said to be responsible for the Sahelian drought in 1973 stretching from the Atlantic Ocean in the west to the Red sea in the east and from the Sahara desert in the north to the Savannas of the south (Tarhule et al., 2002). Past drought occurrence over this region affects agricultural activities, thus brought crop failure and livestock loss to large stretches of northern Nigeria which resulted to food insecurity and varying levels of land degradation problems. For example, Okorie (2003) noted that during the drought of $1972-1973$, about 300, 000 animals died and farm yields dropped by about 60 percent which results in famine in the Northern Nigeria. This inconsistency in the precipitation amount is expected to get worsen with predicted climate change and the aerial extend of drought-affected regions are projected to increase, which could have adverse effects on agriculture, IPCC (2007); Mir et al. (2012). Climatic consequences adversely affect the region in the face of fluctuating rainfall regime. The Northern Nigeria climate fluctuates because this part of the country falls to Sudan-Sahel ecological zone of West Africa which is associated with a long dry season. However, since the early $70 \mathrm{~s}$, climatic anomalies in the form of recurrent droughts, frightening dust storms and rampaging floods have repeated their occurrence on several occasions, creating short-duration climatic oscillations as against the normal cycles of large amplitudes (Omotosho, 2000).

Drought is a water related disaster that is capable of enhancing losses of life, human suffering and causing damage to the environment and economy of any nation. Therefore, there is need to monitor such event using remotely sensed data which has the advantage of synoptic overview, repetitive coverage, cost effectiveness and availability (Agnew, 2000).

Climate has impacted inevitably on the expanding human environment and on the condition of vegetation (Xu et al., 2013; Gao et al., 2014). Recent studies have examined this climatic change consequence on vegetation (Pettorelli et al., 2005; Piao et al., 2006a; Chen et al., 2013; Vicente-Serrano et al., 2013). Different kinds of vegetation indices are available, but Normalized Difference Vegetation Index (NDVI) is the simplest, efficient and commonly used one, Liu and Huete (1995). Satellite data processed into Normalized difference Vegetation Indices (NDVI) can serve as indicator of a region drought pattern because it has the capability of mapping deficiencies in rainfall and thereby portray the meteorological and/ or agricultural drought pattern both timely and spatially (Jain et al., 2008). The normalized difference vegetation index (NDVI) has many merits, such as the simplicity of its algorithm and its ability to roughly differentiate vegetated areas from other land cover types; it is also more effective at identifying green vegetation than are other methods that rely on a single band (Leprieur et al., 1994; Chuai et al., 2013). The NDVI is commonly used to monitor changes in vegetation and land cover, and to investigate the responses of vegetation to regional and global climate change (e.g., Piao et al., 2006a; Yu et al., 2010; Shen et al., 2014, 2015; Xu et al., 2015).

Normalized Difference Vegetation Indices as a measure or estimate of the amount of radiation absorbed by plants, the amount of this radiation absorbed by plant is directly related to the amount of water loss by plant to the atmosphere by the process of evapo-transpiration. The evapo-transpiration is constrained by the amount of water available in the soil, and for the relatively low rainfall amount, the 
amount of soil water availability is constrained by rainfall. Hence NDVI correlates with rainfall (Rowland et al, 1996). Therefore, remote sensing and geographical information systems (GIS) can be put to effective use in forecasting and monitoring drought. Vegetation cover is used as prime indicator because it is widely accepted that the inability of vegetation survival in the absence of water is highly inevitable, so there is almost complete destruction in rain fed area in severe drought condition. Though, drought is a recurrent phenomenon, but the integration of remotely sensed data and GIS application provides timely information about the onset of drought, extent, intensity, duration and impacts can limit drought related disaster. It was in this context that this study used Landsat data and monthly rainfall data to evaluate the vegetation response to drought over the Sudano-Sahelian part of Nigeria.

\section{MATERIALS AND METHODS}

Study area: The study area covers eleven (11) synoptic stations in the Sudano-Sahelian region of northern Nigeria between latitude $10^{\circ} \mathrm{N}$ and $14^{\circ} \mathrm{N}$ and longitude $4^{\circ} \mathrm{E}$ and $14^{\circ} \mathrm{E}$ and lies immediately to the south of Sahara desert (Fig. 1).

The climate of the zone is Semi-arid with alternating wet and dry seasons. The rainfall in this region is less than $1000 \mathrm{~mm}$ per annum and occurs in only about five months in the year, especially between May and October. The rainfall intensity is very high between the months of July and August and there is intrazonal difference in the amount of rainfall received by the Sudano-Sahelian region. The southern part receives more rain and is less variable compared to the northern section

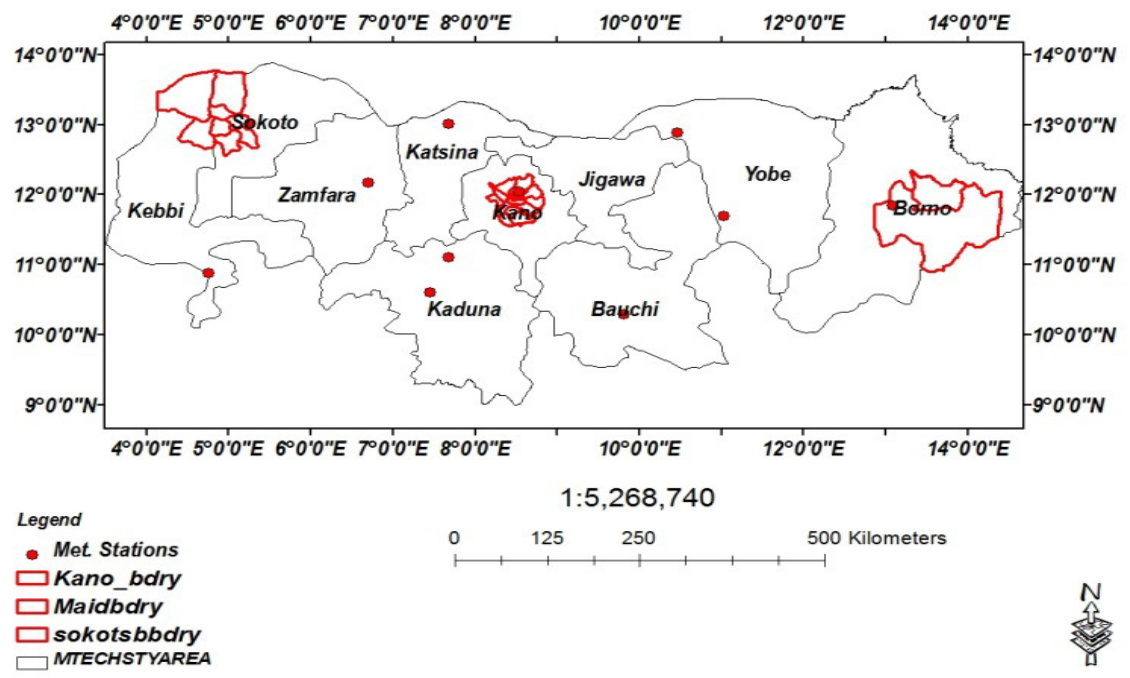

Fig. 1: Map showing the Study Area

Data Collection: Meteorological data (monthly Rainfall amount in $\mathrm{mm}$ ) was obtained for drought analysis over all the meteorological stations (as indicated in Figure 1) present and functioning in the study area for the period of 40years (1971-2010) from Nigeria Meteorological Agency (NIMET), Oshodi in Lagos.

Landsat images covering the selected part of Sokoto, Kano and Borno within the study area were acquired for three different epochs: 1986 (TM), 2000 (ETM+) and 2005(ETM+) from United State Geological Survey (USGS) online archives (www.usgs.gov/).

The local government boundary map and Nigerian Administrative map on the scale of 1:15,140,906 obtained from National Space Research and Development Agency, Abuja (NASRDA) was also used. The details of the data used in this study were presented on Table 1.

Drought analysis: Drought analysis was made by SPI, NDVI and Greenness Index.

Computation of standardized precipitation index (SPI): SPI is an index that was developed to quantify precipitation deficient at different time scales as a result of the effort made by Edward and McKee (1997) and in their precursor work (McKee et al. 1993); they recognized the importance of studying relative departure of rainfall from normality. Therefore the transformation of the original precipitation values (of any specific period) into SPI for each station can be computed as follows; 
Table 1: Details of data acquired and Source

\begin{tabular}{|c|c|c|c|c|c|c|}
\hline $\mathrm{S} / \mathrm{N}$ & DATA TYPE & SENSOR & PATH/ROW & $\begin{array}{l}\text { DATE OF } \\
\text { PRODUCTION }\end{array}$ & SCALE & SOURCE \\
\hline \multirow{8}{*}{1.} & \multirow{8}{*}{$\begin{array}{l}\text { Landsat Image } \\
\text { (Band } 4,3,2)\end{array}$} & TM & $188 / 052$ & $17-11-1986$ & \multirow{8}{*}{$30 \mathrm{~m}$} & \multirow{8}{*}{$\begin{array}{l}\text { Usgs } \\
\text { (online) }\end{array}$} \\
\hline & & & $191 / 051$ & $10-11-86$ & & \\
\hline & & \multirow{6}{*}{ ETM+ } & \multirow[t]{2}{*}{$188 / 052$} & $11-08-2000$ & & \\
\hline & & & & $12-10-2005$ & & \\
\hline & & & \multirow[t]{2}{*}{$185 / 052$} & $10-11-2000$ & & \\
\hline & & & & $23-10-2005$ & & \\
\hline & & & \multirow[t]{2}{*}{ 191/051 } & - & & \\
\hline & & & & $09-11-2005$ & & \\
\hline 2. & \multicolumn{3}{|c|}{$\begin{array}{l}\text { Meteorological Data } \\
\text { (Monthly Rainfall) }\end{array}$} & $\begin{array}{l}1971-2010 \\
\text { (40years) }\end{array}$ & $\mathrm{mm}$ & NIMET \\
\hline 3. & \multicolumn{3}{|c|}{ Administrative and Local government Map of Nigeria } & 2005 & $1: 15,140,906$ & NASRDA \\
\hline
\end{tabular}

(Source: Field survey, 2015)

$\operatorname{Mean}(\chi)=\frac{(\mathrm{Ex})}{\mathrm{N}}$

where, $\boldsymbol{\chi}=$ mean rainfall for the ith station, $\mathbf{X}=$ rainfall for the ith station and kth observation, $\mathbf{N}$ is the number years of the study (40)

Standard Deviation $\left(\sigma_{\mathrm{i}}\right)=\frac{\sqrt{\Sigma}(\mathrm{x}-x)^{2}}{\mathrm{~N}}$

Where $\boldsymbol{\sigma} \mathbf{i}=$ standardized deviation for the ith station

Skew $=\left[\frac{\mathrm{N}}{(\mathrm{N}-1)(\mathrm{N}-2)}\right] \Sigma\left[\frac{(\mathrm{x}-\gamma)}{\sigma_{\mathrm{i}}}\right]^{2}$

The precipitation data are transformed by the $\log$ normal (ln) and the mean of those values are computed. The transformed values are further described by the constant A, the shape $(\alpha)$ and the scale $(\beta)$ parameter.

$$
\begin{aligned}
& \log \operatorname{moan}\left(\chi_{\mathrm{in}}\right)-\frac{[\mathrm{ln}(\mathrm{x})]}{\mathrm{N}} \\
& \mathrm{A}=\ln (\chi)-\chi_{\mathrm{n}} \\
& \text { Shape }(\mathrm{x})-\left[\left(\frac{1}{4 \mathrm{~A}}\right)\left(1+\sqrt{\left(1+\left(\frac{4 \mathrm{~A}}{3}\right)\right)}\right)\right] \\
& \text { Scale }(\beta)=\frac{\mathrm{X}}{\mathrm{a}}
\end{aligned}
$$

The ln values are transformed by the gamma distribution, incorporating the shape and the scale values:

Cumulative Gamma transform $\left(X_{g}\right)=\frac{1}{\beta^{x} \Gamma(\omega)} \int_{0}^{x} X^{a-1} e^{-\frac{X}{\beta}} d X$

Where:

$$
\begin{aligned}
& \alpha>0, \beta>0, X>0 \\
& \text { as } \quad \text { Excel function, }
\end{aligned}
$$$$
\text { GAMNADISI' }(X, \alpha, \beta \text {, true })
$$$$
\text { transform }(t)=\sqrt{\operatorname{lin}\left(\frac{1}{\left(\mathrm{u}_{g}\right)^{2}}\right)} \quad \text { for } 0 \leq \mathrm{X}_{g} \leq 0.5(9)
$$

$$
\begin{aligned}
& \text { ttransform }(t)=\sqrt{\ln \left(\frac{1}{\left(1-X_{g}\right)^{2}}\right)} \quad \text { for } 0.5<X_{g}<10(10)
\end{aligned}
$$

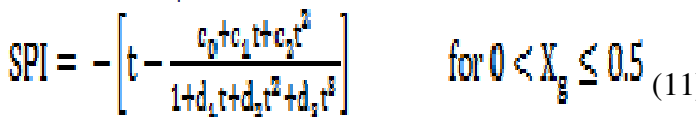

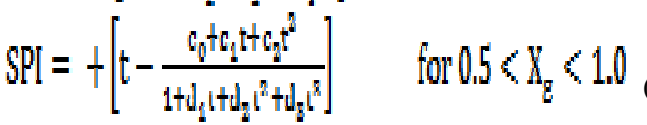

Where,

$$
\begin{aligned}
& c_{0}=2515517, c_{1}=0.802853, c_{7}=0,010328, d_{1}=1.432788, d_{2}=0.189269, d_{3} \\
& =0.001300
\end{aligned}
$$

The resultant SPI was interpolated using Inverse Distance Weighted (IDW) interpolation technique in ArcGIS 9.3 environment. The underlying premise for IDW interpolation is based on the assumption that things that are close to one another are more alike than those that are farther apart, the interpolated maps were later reclassified into different drought severity classes and finally obtained Drought Severity Map.

Vegetation Response Analysis: Vegetation analysis was made by NDVI and Greenness Index.

Data Pre-processing: All the Landsat datasets have been rectified to a common UTM (Universal Transverse Mercator) projection and(w)WG 84 datum. Sub-setting was done in Erdas Imagine 9.3 to limit the images to the boundary of selected local government area with Sokoto, Kano and Borno State using the Area of Interest (AOI) created from shapefile map of the study area.

Generation of Greenness Index (NDVI) and Greenness Index image: The NDVI calculation was performed to find out the change in vegetation during the selected period of this study. The year 1986, 2000 and 2005 were selected due to satellite data 
availability and the following algorithm developed by Rouse et al., (1974) was used for the analysis.

$$
N D V I=\frac{(N I R-R)}{(N I R+R)}
$$

Where: NIR and $\mathrm{R}$ are the reflectance in the nearinfrared (band 4) and red (band 3) portion of electromagnetic spectrum respectively.

Greenness Index Map was developed based on the idea that the radiation within the range of $0.58 \mu \mathrm{m}$ to $0.68 \mu \mathrm{m}$ (Visible or red band) of electromagnetic spectrum are highly absorbed by the chlorophyll of plant leaves, and those within $0.72 \mu \mathrm{m}$ to $1.1 \mu \mathrm{m}$ (near-infrared) are highly reflected by the vegetation. Therefore, vegetated areas will yield high values (positive NDVI value) due to their relatively high near-infrared reflectance and low visible reflectance. In contrast, water, clouds and snow have larger visible reflectance than near-infrared reflectance. Thus, these features yield negative index values. Rock and bare soil have similar reflectance in the two bands and result in vegetation indices near zero. Greenness Index (GI) map was generated from reclassified NDVI maps in ArcGIS 9.3 environment. Greenness Index (GI) map reveals the spatial extent of vegetation cover over the selected part of the study area.

\section{RESULT AND DISCUSSION}

Standardized precipitation index analysis: Figures 2 and 3 show the SPI at each station in Sahel Savanna and Sudan Savanna over the years considered in this study. These graphs reveal how SPI were distributed around the normal (SPI of -0.5 (Mckee et al., 1993)) over the years with locations. The graphs were interpreted using the SPI threshold values adapted from Mckee et al. (1993) as shown in Table 2.

Table 2: Classes for Meteorological drought category

\begin{tabular}{|l|l|l|}
\hline Categories & Description & SPI \\
\hline D0 & No Drought & -0.5 and above \\
\hline D1 & Abnormally dry & $-0.5--0.7$ \\
\hline D2 & Moderate Drought & $-0.8--1.2$ \\
\hline D3 & Severe Drought & $-1.3--1.5$ \\
\hline D4 & Extreme Drought & $-1.6--1.9$ \\
\hline D5 & Exceptional Drought & -2 or less \\
\hline
\end{tabular}

(Adapted from Mckee et al. (1997))

The highest peak of drought episode was observed over Sokoto in 1987 and again over Maiduguri in the year 1983 (Fig. 2). Most stations in the Sahelian zone actually experienced a varying levels of drought severity in 1973, 1982-1984 and 1987 as their values fell below normal on the graph indicating a dry condition over the region. Beginning from 1992 downward, there was improvement in the average weather condition over most of the Sahelian stations as the SPI value was close to and above which indicate less or no drought event. Between year 2000 and 2010, the results via the graph showed that there had been a drastic reduction in the degree of dryness over the region as the peak across the stations in the Sahel was found close to normal and above indicating these periods were wet. Figure 3 show the graphical representation of the SPI value distribution across the stations in the Sudan Savanna zone of the study area over the years considered. The highest peak below the normal was evident over Yelwa station in 1983 while the highest above the normal was observed over the same station in 1999 indicating extreme wet condition over the station. Although, some stations like Yelwa, Bauchi and Kaduna in the region (Sudan) were hit by the drought episodes of 70s and 80s but the severity was less intense compared to that of Sahelian zone. Despite the fact that there was improvement in rainfall amount in the Northern part of Nigeria in 1990s towards 2010, negative SPI was still observed over Kaduna in 1994, 1998 and 20052007. That simply indicated that Kaduna station was still in dry condition during those periods previously mentioned. The result of this analysis was in line with that of Okorie (2003), which reported that based on the precipitation data, many years of drought episode were record in all the 14 States of Nigeria covered in the study over but there was dramatic decline in the drought occurrence in the early 90 s towards the year 2000.

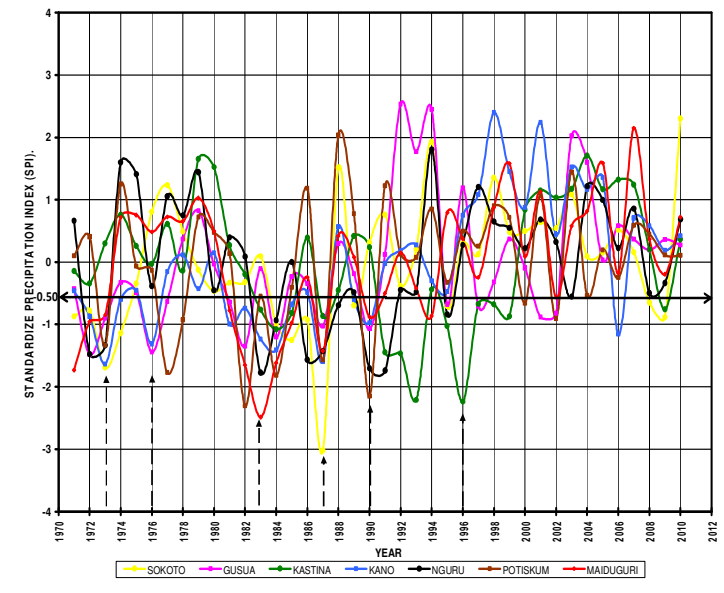

Fig 2: A graph of resulting SPI values against each study year for period of 1971-2010 over each station in Sahelian Zone. The Black solid horizontal line on the graph indicates the line of -0.5 SPI value (Normal) on the graph. 


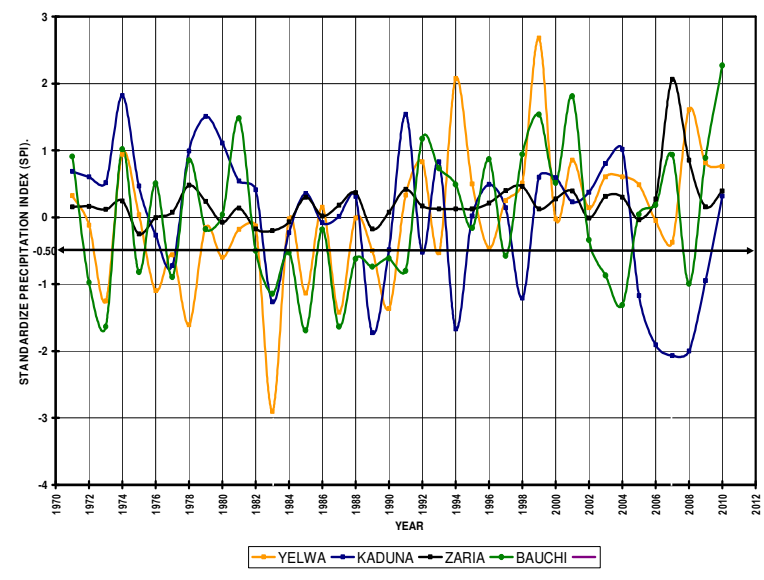

Fig 3: A graph of resulting SPI values against each study year for period of 1971-2010 over each station in Sudan Savanna Zone. The Black solid horizontal line on the graph indicates the line of -0.5 SPI value (Normal) on the graph.

Drought Impact Assessment on Vegetation: Two different epochs was selected for the impact assessment. A dry year, 1986 and a wet year 2005 as confirmed from SPI analysis results (Figure 2 and Figure 3). Greenness Index Maps for the same years over the selected part of the study area were also brought together and compared.

Figure 4 and 5 shows the spatial distribution of drought occurrence and their intensity over the study area in the year 1986 and an average environmental condition of the same region in 2005 respectively, together with the status of vegetation in each of the respective years. Figures 4 present a drought scenario of 1986 and vegetation response analysis result of the same year over the selected part. The selected parts for vegetation response analysis were Sokoto, Kano and Borno States.

Figure 4d revealed that the year 1986 was a dry year except Kano State where near normal condition was observed.

Figures 4a, 4b, 4c and Figures 5a, 5b, 5c are Greenness Index Maps obtained from each of the selected parts of the study area for the year 1986 and 2005 respectively, after reclassification of the NDVI analysis results in ArcGIS using NDVI threshold values adapted from Kongoti, (2005) shown in Table 3. These maps consist of three distinct features namely; Vegetation, water-body/Built-up area and Bare-Surface, purposely done for easy assessment of change in the vegetative part of the study area.

Table 3: Greenness Index threshold values

\begin{tabular}{|l|l|}
\hline Land Cover Categories & NDVI Values \\
\hline Dense Vegetation & $+0.04-+1.00$ \\
\hline Less Dense Vegetation & $+0.04-+0.07$ \\
\hline Bare Surface Area & $-0.08-+0.04$ \\
\hline Water Body & $-0.08--1.00$ \\
\hline
\end{tabular}

Source: (Adapted from Kongoti, (2005)
Figures $4 a, 4 b$ and $4 c$ revealed the effect of the dry weather condition on the vegetation as more area was covered with sand and reflect as bare surface on the imagery.

It could be observed that during a drought year (1986), vegetation responds to the dryness in weather condition by stunt growth which withers and later died off and in turns cause reduction in their population. The depletion of the vegetation and striking of water bodies caused more bare soil to be exposed. This finding was in line with the report made by Sergio et al., (2013) that plants usually have a poor adaptability to water shortage but the vegetation response to drought depends on the characteristic of the drought time-scales for each biome. The area or the spatial extent covered by the vegetation compared to the bare surface as revealed on Figures $4 \mathrm{a}, 4 \mathrm{~b}$ and $4 \mathrm{c}$ is much more less over Sokoto, Kano and Borno States.

Though, Kano State appears to be under the influence of near normal condition and yet the vegetation analysis carried out over the state still show less vegetation cover and more bare soil. This is because the drought incidence was experienced in the State (Kano) in the recent years (1984 \& 1985) and the impact is still manifesting on the vegetation in the year 1986 which is in line with the FAO report of $3^{\text {rd }}$ day of June 1999 which indicated that drought impact in a particular region at a specific time can be later felt in the future.

Figure $5 \mathrm{~d}$ show that wet condition prevailed over the study area in 2005 as moderate wet and severe wet condition was recorded over Kano and Borno States. Also the Greenness Index map over Sokoto, Kano and Borno States show there is improvement in vegetation cover and drastic reduction in bare surface while water bodies also improve (Figures 5a, b \& c). Hence, it is important to note that the recent years over the study area until 2005 have witness wet condition. 


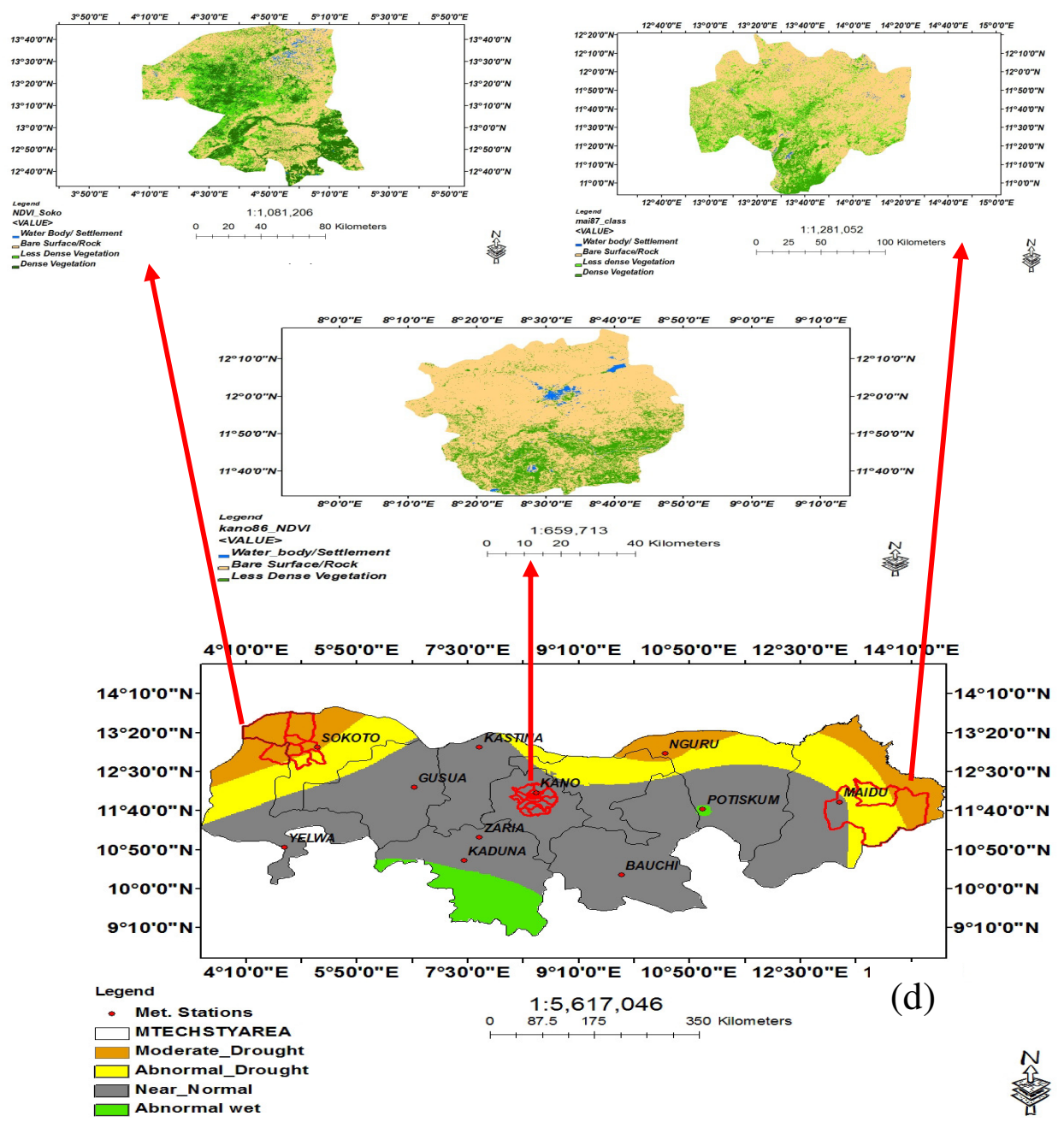

Fig 4: Showing Drought Scenario and Vegetation Response characteristic for 1986 over the study area

Conclusion: This study so far revealed that the Sudano-Sahel region of Nigeria has been threatened with many years of drought episodes in 1970s and 1980s. This had in turn terribly influenced the growth of the vegetation in the region by causing tremendous reduction in their population. As the relationship between this abnormality in the average weather condition and vegetation within an ecosystem are directly linked. Drastic reduction in vegetation and their ill growth posed threat on the people of this area living standard as their major source of income (agriculture) as confirmed by the literatures is rainfed. Also the Vegetation Cover maps depict increase in the spatial extent in 2000 relative to 1986 which simply mean an improvement in rainfall over the region.

FAO report of $3^{\text {rd }}$ day of June 1999, which indicated that drought impact in a particular region at a specific time can be later felt in the future, was also confirmed in this study. SPI analysis result and Drought Spatial Pattern for 1986 show that though, the near normal condition prevailed over Kano but the vegetation analysis result depict the region was still dry as there was no visible improvement in the vegetation cover over the State. But it was noted that the recent years (1981-1985) over Kano was recorded as drought year which the impact was believed to still be manifesting over the area in 1986 even when the Near normal condition has returned to the area. In the early 1990s the dryness started to reverse as near normal condition was seen to be spreading over the area towards 2000 which show the return of abundant rainfall to the region. The beginning $21^{\text {st }}$ century up till 2010 can be describe as wet year over most part of the Sahel and the Sudan savanna as depicted on the graphs. 


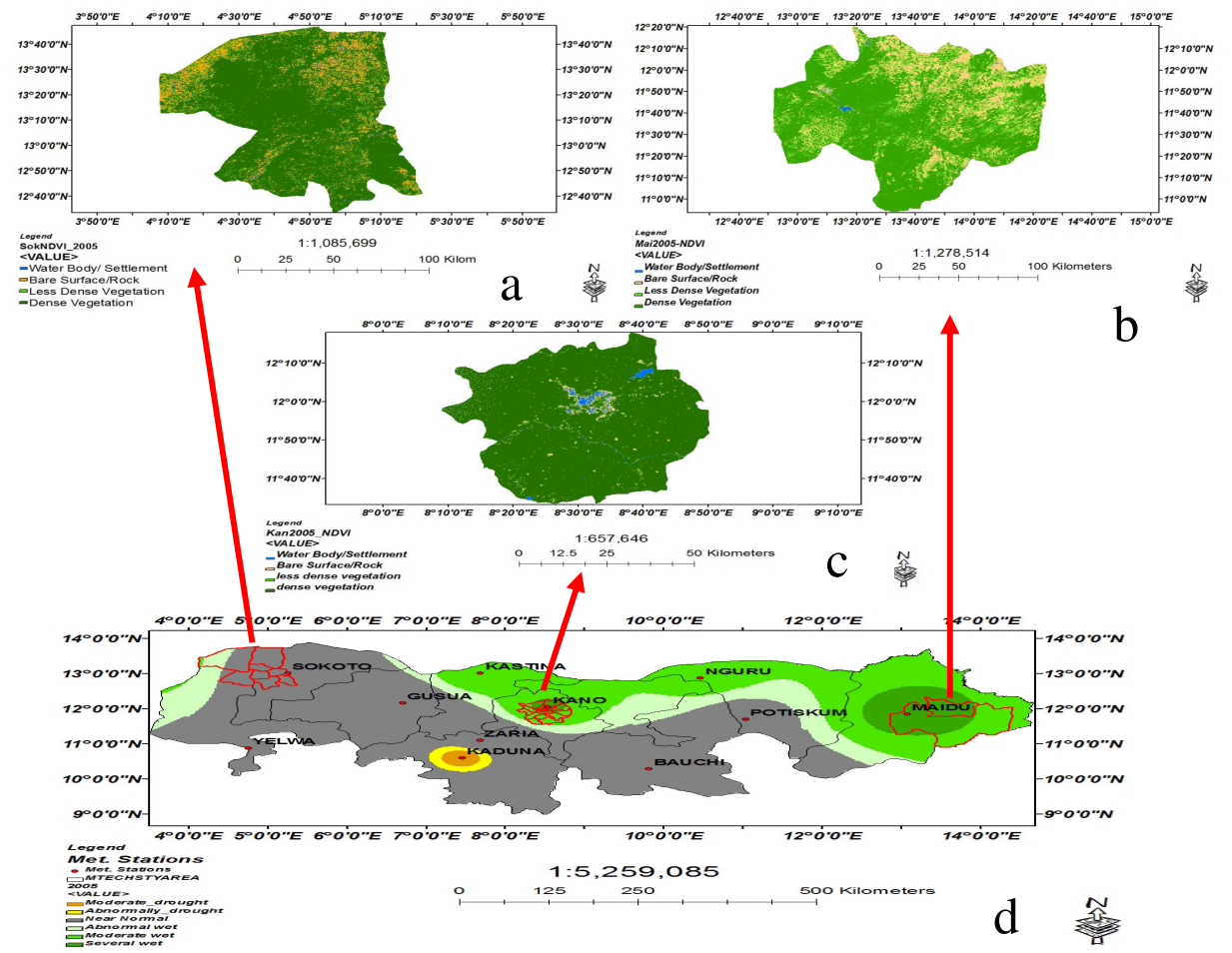

Fig 5: Showing Drought Scenario and Vegetation Response characteristic for 2005 over the study area

The result gotten from Drought and Vegetation Response analysis in 1986, confirmed that whenever there is drought outbreak, vegetation respond by depreciating in growth due insufficient or availability of plant available water in the soil. As the drought persist over a long period of time, it definitely results in vast reduction in floral population in an ecosystem which may also leads to increase in spatial extent of bare surface, decrease in fauna population as the region would no longer conducive for living

Acknowledgements: My profound gratitude goes to NASA and U.S Geological Survey for the provision of the Satellite data used for this study. I would also like to appreciate the National Space Research and Development Agency, Abuja (NASRDA) Nigeria for the data released for this project, thank you very much.

\section{REFERENCES}

Agnew, CT (2000). Using the SPI to identify drought. Drought Network News 12(1): 6-12.

Chen, H; Zhu, Q; Peng, C; Wu, N; Wang, Y; Fang, X; Gao, Y; Zhu, D; Yang, G; Tian, J;

Kang, X; Piao, S; Ouyang, H; Xiang, W; Luo, Z; Jiang, H; Song, X; Zhang, Y; Yu, G; Zhao, X; Gong, P; Yao, T; Wu, J (2013). The impacts of climate change and human activities on biogeochemical cycles on the Qinghai-Tibetan Plateau. Global Change Biology, 19, 2940e2955.
Chuai, X; Huang, X; Wang, W; Bao, G (2013). NDVI, temperature and precipitation changes and their relationships with different vegetation types during $1998 \mathrm{e} 2007$ in Inner Mongolia, China. International Journal of Climatology, 33, 1696e1706.

Edwards, DC; McKee, TB (1997). Characteristics of 20th century drought in the United States at multiple time scales. Atmospheric Science Paper. 634: 1-30.

FAO (1999). Report on the Agro-Ecological Zones Project. Vol. 1. Ethodology and Results for Africa, Rome, FAO.

Gao, J; Zhang, Y; Liu, L; Wang, Z (2014). Climate change as the major driver of alpinegrasslands expansion and contraction: a case study in the Mt. Qomolangma (Everest)National Nature Preserve, southern Tibetan Plateau. Quaternary International, 336, 108e116.

Hess, TM; Stephens, W; Maryah, U M (1995). Rainfall trends in the North East Arid Zone of Nigeria 19611990. Agric. For. Meteorol. 1995, 74, 87-97. 2.

Jain, SK; Keshri, R; Goswani, A; Sarkar, A; Chaudhry, A (2008). Identification of drought-vulnerable areas using NOAA AVHRR data. International Journal of Remote Sensing Vol. 30, No. 10, 20 May 2009, 26532668.

Leprieur, C; Verstraete, MM; Pinty, B (1994). Evaluation of the performance of various vegetation indices to retrieve vegetation cover from AVHRR data. Remote Sensing Reviews, 10, 265e284.

Liu, HQ; Huete, AR (1995). A feedback based modification of the NDV I to minimize canopy background and 
atmospheric noise. IEEE Transactions on Geoscience and Remote Sensing, 1995, 33, 457-465.

Mckee, TB; Doesken, NJ; Kleist, J (1993). The relationship of drought frequency and duration to time scales. 8th Conference on Applied Climatology, 17-22 January, Anaheim, CA, pp. 179-148.

Mir, R R; Zaman-Allah, M; Sreenivasulu, N; Trethowan, R; Varshney, R K (2012).

Integrated genomics, physiology and breeding approaches for improving drought tolerance in crops. Theoretical and Applied Genetics, 125, 625-645.

Omotosho JB, Balogun AA, Ogunjobi K (2000). Predicting monthly and seasonal rainfall onset and cessation of the rainy season in West Africa using only surface data. Int J Climatol 20: 865-880

Okorie, FC (2003). Studies on Drought in the SubSaharan Region of Nigeria Using Satellite Remote Sensing and Precipitation Data. Retrieved from: http://www.mathaba.net/gci/docs/ research/nigeriadrought.html. (Accessed date: September 09, 2017)

Pettorelli, N; Vik, JO; Mysterud, A; Gaillard, JM; Tucker, CJ; Stenseth, NC (2005). Using the satellite-derived NDVI to assess ecological responses to environmental change. Trends in Ecology \& Evolution, 20, 503e510.

Piao, S; Mohammat, A; Fang, J; Cai, Q; Feng, J; (2006a). NDVI-based increase in growth of temperate grasslands and its responses to climate changes in China. Global Environmental Change, 16, 340e348.

Rouse, JW; Haas, RH; Schell, JA; Deering, DW (1974). Monitoring Vegetation Systems in the Great Plains with ERTS, In: Fraden S.C., Marcanti E.P. and Becker M.A. (eds). Third ERTS-1 Symposium, 10-14 Dec. 1973, NASA SP-351, Washington D.C. NASA, pp. 309-317.
Rowland, J; Nadeau, A; Brock, J; Klaver, R; Moore, D (1996). Vegetation Index for Characterizing Drought Patterns. Raster Imagery in Geographic Information Systems. Santa Fe, New Mexico, Onward Press, pp. 247-254.

Tarhule, A; Woo, MK (2002). Adaptations to the dynamics of rural water supply from natural sources: A village example in semi-arid Nigeria. Mitig. Adapt. Strateg. Glob. Chang. 2002, 7, 215-237.

Sergio, M; Vicente-Serrano; Célia , G; Jesús, JC; Santiago, B; RicardoTrigo, JI; López-Moreno, César, AM; Edmond, P; Jorge, LL; Jesús, R; Enrique, MT; Arturo, SL (2013). Response of vegetation to drought time-scales across global land biomes. Proc Natl Acad Sci U S A. 2013 Jan 2; 110(1): 52-57.

Shen, M; Zhang, G; Cong, N; Wang, S; Kong,W; Piao, S (2014). Increasing altitudinal gradient of spring vegetation phenology during the last decade on the QinghaieTibetan Plateau. Agricultural and Forest Meteorology, 189e190, 71e80.

Vicente-Serrano, SM; Gouveia, C; Camarero, JJ; Begueria, S; Trigo, R; Lopez- Moreno, JI; Azorin-Molina, C; Pasho, E; Lorenzo-Lacruz, J; Revuelto, J (2013). Response of vegetation to drought time-scales across global land biomes. Proceedings of the National Academy of Sciences 110, 52e57.

Xu, Y; Yang, J; Chen, Y (2015). NDVI-based vegetation responses to climate change in an arid area of China. Theoretical and Applied Climatology, 1e10.

Yu, H; Luedeling, E; Xu, J (2010). Winter and spring warming result in delayed spring phenology on the Tibetan Plateau. Proceedings of the National Academy of Science, 107, 22151e22156. 